Игорь Иванович КАЛИГАНОВ 


\section{СОЗДАНИЕ ВИРТУАЛЬНОГО МУЗЕЯ СЛАВЯНСКИХ КУЛЬТУР КАК НАСУЩНАЯ ЗАДАЧА СОВРЕМЕННОЙ СЛАВИСТИКИ ${ }^{1}$}

\section{Аннотация:}

В статье речь идет о необходимости создания виртуального Музея Славянских Культур, потребность в котором в наше время все убыстряющейся цифровизации различных сфер жизни представляется очевидной. Размещенные в нем материалы о культурах южных, восточных и западных славян от древности до наших дней предполагается размещать на веб-сайтах не только на русском, но и на английском языке - самом распространенном языке в мире, которым в большей или менышей степени владеют 1,5 млрд. человек. Последнее позволит осуществить прорыв в распространении знаний о культурах славян в инославянской среде. Экспозиция в таком музее не будет дублировать материалы, имеющиеся в многочисленных специализированных энциклопедиях, справочниках и Википедии. Статыи для Музея будут созданы лучшими специалистами, которые сумеют выстроить точный культурный ландшафт славянского мира, не загружая сознание посетителей второстепенными и ненужными им фактами. Автор предлагает оптимальную, по его мнению, трехчастную структуру музейных статей, которые в сопровождении визуальных материалов будут способны удовлетворить самые разнообразные интересы и вкусы посетителей создаваемого Музея.

\section{Ключевые слова:}

Виртуальный Музей Славянских Культур, прорыв в распространении знаний о славянских культурах в мире, оптимальный формат музейных статей.

Abstract: I.I. Kaliganov "The Creation of a virtual Museum of Slavic Cultures as an ACTUAL TASK OF MODERN SLAVISTICS".

The article refers to the need to create a virtual Museum of Slavic Cultures. The task in our time of rapid digitalization of different spheres of life seems obvious. Its materials on the cultures of Western and Southern Slavs from ancient times to the present day are to be posted on websites not only in Russian, but also in English, the most common language in the world, which speak more than 1,5 bln people. This will make possible a breakthrough in the dissemination of knowledge about Slavic cultures to the nonslavic environment. The exposition in such a museum will not duplicate the materials available in numerous specialized encyclopedias, handbooks and Wikipedia: articles for the Museum will be created by the major specialists who will be able to build an accurate cultural landscape of the Slavic world, without loading the consciousness of visitors with secondary and unnecessary facts. The author proposes an optimal threepart structure of museum articles, which, accompanied by visual materials, will be able to satisfy a wide variety of interests and tastes of visitors to the Museum being created.

\section{Keywords:}

Virtual Museum of Slavic Cultures, Dissemination of knowledge about Slavic cultures in the world, optimal format of museum articles.

\footnotetext{
1 Работа выполнена при финансовой поддержке РФФИ (грант № 18-512-76004).
} 
$\Pi$ роцесс цифровизации во многих областях нашей жизни приобретает сегодня все большую динамику. В электронно-цифровой формат переводятся документы самого различного характера: Это и бухгалтерский учет, и проектно-конструкторские чертежи, и библиотечные каталоги, и наиболее ценные научные издания. Молодежь все чаще отдает предпочтение электронным носителям информации, а не бумажным. В метро пассажиры ныне читают не традиционные печатные книги, а их электронные варианты. Пожилые люди дома раскрывают не купленный в книжном магазине нашумевший роман, а скачивают его текст из Интернета.

В этом же русле цифровизации находятся и материалы книги, которую вы взяли в руки. Помещенные в ней материалы связаны с международным трехсторонним (Бельгия-Болгария-Россия) проектом «Разнообразие и взаимодействие культур южных и восточных славян в XI-XX вв.», победившим на конкурсе Европейского союза ERA NET RUS Plus. Они существуют не только в печатном, но и в электронном виде и размещены на сайтах Болгарской академии наук (cм. https://sesdiva.eu) и бельгийского Гентского университета на болгарском, русском и английском языках. Конфигурация виртуального музея письменных культур южных и восточных славян была разработана на совещании координаторов проекта (главный координатор, болгарский проф. А. Милтенова, бельгийский координатор проф. Д. Штерн и российский - проф. И.И. Калиганов) летом 2018 г. в Гентском университете. Ими было принято решение о создании в музее десяти «залов»: 1) древнейшие и известнейшие памятники литературы и письменности южных и восточных славян; 2) миграция книг, текстов и идей: литературный и культурный обмен между славянским Югом и Востоком; 3) центры культурной коммуникации в периоды Средневековья и Нового времени (Афон, Киев, Москва, Одесса, Рильский монастырь и др.); 4) популярные святые, авторы и произведения; 5) собиратели рукописей и книг; рукописные собрания и библиотеки; 6) начало и распространение индивидуального чтения в Slavia Orthodoxa; 7) русская эмиграция на Балканах; 8) эмигрантская литература и культура в веках; 9) Национальное возрождение славян (балканские писатели XVIII-XIX вв. о России); 10) писатели и ученые XIX-XX вв. ${ }^{2}$

Утвержден был и формат будущих музейных статей. Предполагалось, что их объем не должен превышать четырех-пяти стандартных страниц, включая библиографию, а сами они должны сопровождаться 5-10 иллюстрациями. Начавшаяся конкретная работа по реализация данного проекта натолкнулась, однако, на известные трудности, которые касались как обшей конфигурации задуманного виртуального музея, так и подготавливаемых для него статей. Общее число участников проекта из трех стран составляло всего 23 человека, и полнокровно заполнить «экспозицией» все 10 залов му-

${ }^{2}$ См.: Калиганов И., Милтенова А. Виртуален музей на писмените култури на южните и източните славяни от XI-XX в. // Старобългарска литература. Кн. 59. София, 2019. С. 262-267. 
зея за два с небольшим года (срок реализации проекта) они при всем своем желании, разумеется, были не в состоянии. «Прокрустовым ложем» оказался и утвержденный максимально допустимый объем статей. Участники проекта очутились на перепутье: с одной стороны, им хотелось рассказать об объекте повествования привычным для себя академическим языком, используя в статьях сноски и фундированный научный аппарат, а с другой стороны, они сознавали, что музей не должен создаваться для немногих узких специалистов, отпугивая широкий круг посетителей чрезмерной научностью и обилием в общем-то не нужных им научных фактов. В любом случае принятый на Гентском совещании максимально допустимый объем музейных статей соблюдать было просто нереально.

Помещенные в сборнике свыше 60 статей российских участников проекта (все они являются учеными Института славяноведения РАН) отражают различные этапы практической разработки наиболее оптимального формата музейных публикаций. В нем есть чисто академические работы с многочисленными сносками и солидными списками научной литературы (примером могут служить работы М.М. Фроловой, К.В. Мельчаковой и частично Ю.А. Лабынцева), присутствуют неудачные попытки перехода к более приемлемому музейному формату и научные публикации с полным соблюдением постепенно сложившихся новых требований. Последних статей в данном выпуске большинство, и их легко распознать по отсутствию сносок, лаконичному списку приводимой научной литературы и усилению при повествовании герменевтического начала. Практически все авторы академических публикаций сборника создали и их «музейные» варианты для размещения на веб-сайте Болгарской академии наук. Они, также как и работы других российских участников проекта, были переведены на английский язык, выйдут во втором выпуске «Материалов для виртуального МСК» в печатном виде и будут размешены на сайте Гентского университета. При создании статей удалось реализовать уникальные возможности Института славяноведения РАН, в стенах которого собраны специалисты по всем странам славянского Юга и Востока. Читатель найдет в данном выпуске и на упомянутых сайтах статьи наших ученых о культурах Беларуси, Болгарии, Боснии и Герцеговине, России, Северной Македонии, Сербии, Словении, Украины, Хорватии и Черногории.

В ходе реализации проекта у меня довольно быстро сложилось убеждение в том, что работу в этом направлении необходимо продолжать и после окончания срока действия гранта. Полученные результаты, по моему мнению, должны стать первым камнем, заложенным в основание виртуального Музея Славянских Культур, причем не только славянского Юга и Востока, но и Запада, и его экспозиция не должна ограничиваться только культурами письменнымиํ. На обложке данного выпуска представлено изображение

3 Соображение об этом было высказано мной в докладе на конференции в октябре 2018 г. См.: Калиганов И.И. Мысли о грядущем Музее Славянских Культур // Тезисы докладов подготовительной научно-практической конференции «Разнообразие и взаимодействие письменных культур южных и восточных славян в XI-XX вв.» в рамках 
среза древа славянских культур, которое отражает несколько наивное, романтичное представление славянофилов XIX в. о единстве славянских культур на протяжении их многовекового развития. На самом деле это развитие было гораздо более сложным и не сводилось к элементарному увеличению числа «годовых колец» и постепенному подрастанию ствола древа вверх. Здесь было бы уместнее говорить о многожильном спиралевидном «кабеле» с то увеличивающимися, то уменьшающимися в поперечном сечении жилами, которые обладают способностью переплетаться между собой, могут взаимно сливаться или разветвляться, способны то умножать, то уменышать свое собственное число, равно, как и диаметр своих пространственно-временных витков.

К изображению среза «древа» я прибегнул исключительно для иллюстрации общей конфигурации будущего виртуального Музея Славянских Культур и выделения в нем главных его составляющих. По мере удаления центра к периферии оптимальным в нем видится присутствие следующих материалов:

а) праславянский язык, древнеславянская мифологии и иные разделы древнеславянского фольклора;

б) памятники письменности и литературы; региональные трансформации праславянского языка на Юге, Востоке и Западе славянского мира вплоть до современности;

в) народная художественная культура;

г) бытовая, культовая и светская архитектура;

д) скульптура;

е) религиозная и светская живопись;

ж) театр;

3) кино;

и) музыка.

Размещение в ВМСК разделов о политической истории славянских государств представляется мне нецелесообразным. В системе общественных наук эта дисциплина является одной из самых лабильных и коньюнктурных. Каждые 30-50 лет по заказу властных структур политическую историю начинают переписывать и переиначивать вслед за очередным наступлением геополитических перемен. Поэтому от размещения в ВМСК материалов подобного рода разумнее отказаться: они станут миной замедленного действия, которая рано или поздно продемонстрирует свою разрушительную силу. Контуры политической истории можно будет использовать лишь пунктирно для обозначения изменчивой конфигурации общих культурных зон, границы которых чаще всего не совпадали с границами политическими.

Значительную опасность при строительстве ВМСК могут представлять национальные и корпоративные факторы. Чрезмерно патриотическое 
стремление строителей к наибольшей репрезентативности своих «национальных» материалов в музее может оказать последнему медвежью услугу. Оно увеличит вероятность появления музейных статей и «экспонатов», относящихся ко второй или третьей категорий культурных явлений, не обладающих ни оригинальностью, ни особой значительностью на фоне мирового культурного ландшафта. То же самое касается и корпоративного фактора: обычно после многолетних научных разысканий ученые настолько проникаются и срастаются со своей областью науки (в нашем случае культуры), что она кажется им более важной по сравнению с остальными ее областями. Это обстоятельство способно привести к завышенной оценке исследователями тех культурных явлений, которыми они занимаются, и к стремлению обеспечить им место в музее. Но ведь никто не станет выставлять в Лувре экспонаты, достойные размещения в краеведческом музее. Точно так же и для экспозиции ВМСК необходимо отбирать самое элитное, самое ценное и достойное - иначе у англоязычных посетителей музея может сложиться мнение о сравнительно невысоком уровне развития славянских культур, как таковых, и о том, что они являются вторичными по отношению к западноевропейским.

Фильтром здесь призваны служить соответствующие словники, составленные на основе разумных квот. Они должны устанавливаться с учетом величины каждой из славянских стран и размеров их вкладов в ту или иную область славянской культуры. Можно, например, дать задание специалистам отобрать для начала 150 имен лучших русских писателей XI-XX вB., 120 польских, 80 чешских, 50 хорватских, 40 сербских и т.д. Разумеется, эти цифры даны мной «навскидку» и в дальнейшем могут быть скорректированы как в сторону их увеличения, так и уменьшения. Размеры вкладов отдельных славянских народов в общеславянскую культурную копилку не всегда находились в прямо пропорциональной зависимости от их численности, в ходе истории их доля в ней, как правило, претерпевала изменения и не являлась равновеликой во всех областях национальной культуры. Аналогичным образом обстоит дело и в архитектуре, живописи, скульптуре, музыке, киноискусстве и других разновидностях культурной деятельности славянских народов.

В ходе работы по реализации проекта по созданию виртуального музея письменных славянских культур южных и восточных славян XI-XX вв. у меня постепенно сформировалось представление и о наиболее оптимальном формате статей для будущего ВМСК ${ }^{4}$. По-моему мнению, их средний объем должен составлять не менее 7-10 страниц с предельным максимумом в 20000 знаков. А сама их структура должна быть не двухчастной, а трехчастной.

\footnotetext{
4 Оно было очерчено мной в моем докладе на уже упомянутой конференции. См.: Калиганов И.. Заметки об оптимальном «музейном» формате при написании статей для виртуального Музея Славянских Культур // Тезисы докладов подготовительной научно-практической конференции «Разнообразие и взаимодействие письменных культур южных и восточных славян в XI-XX вв.» в рамках одноименного международного трехстороннего проекта Бельгия-Болгария-Россия (ERA NET RUS plus, РФФИ 18-512-76004). 23 октября 2018 г. Москва. М., 2018. С. 6-8.
} 
Первую, как уже говорилось, следует создавать в герменевтическом ключе. При работе над ней нужно стремиться не отпугнуть неподготовленного посетителя чрезмерным перечислением вообще-то не нужных ему научных фактов, а постараться простым языком разъяснить ему суть описываемого явления культуры и его уникальность: первый национальный поэт, патриарх военной журналистики, древнейшая датированная рукопись у восточных славян, первый национальный романист и т.д. Обозначения статей в ВМСК, на мой взгляд, не следует уподоблять практике энциклопедий и специальных справочников, в которых даются лаконичные названия памятников или фамилии писателей, а затем начинают более подробный о них рассказ. Видимо, лучше еще в названии известить читателя о сути дальнейшего повествования, т.е. соблюсти своеобразный «этикет» авторов XVIII в., которые куртуазно сразу же извещали своего читателя, о чем будут вести речь. Чтобы не делать название чересчур длинным, вслед за ним можно поместить «титул» из трех-пяти предложений, преследующих ту же цель, что и название. Даже если читатель не станет дальше читать статью, в его памяти останутся факты о том, что Вас.И. Немирович-Данченко, например, является патриархом русской военной журналистики, а А.Д. Чертков был основателем первой бесплатной публичной библиотеки в Москве. Таким образом даже названия статей ВМСК станут играть роль умного «букваря» по славянским культурам для взрослых людей.

В первой части статьи следует также очень точно и лаконично описать суть затрагиваемого явления славянской культуры. С этой задачей способны справиться только специалисты высокой квалификации, обладающие глубокими знаниями не только о самом предмете повествования, но и имеющие ясное представление о сходных явлениях в развитии славянских культур и могущие выстроить реальный культурный масштаб с соблюдением в нем необходимых пропорций. Идеальными исполнителями здесь видятся академические ученые: в первую очередь, те из них, кто владеет искусством слова. Ведь не является секретом то, что многие труды серьезных ученых бывают написаны таким «чугунно-литейным» языком, что отталкивают от себя взявших их в руки читателей. При подготовке первой части нельзя исключать привлечение внешних стилистов, способных превратить трудные тексты в «удобоваримые» и читабельные. Сноски на научные работы в герменевтической части не желательны: они здесь излишни и лишь отвлекают посетителя от герменевтической сути того культурного явления, с которым он знакомится.

Вторая часть статьи будет сокрыта от глаз читателя: доступ к ней станет осуществляться через «тегу» с обозначением «Историография». Ее объем будет составлять 2-3 страницы и иметь сугубо научный характер. Она предназначена для тех ученых, которые захотят ознакомится с историей изучения данного культурного явления подробно. Здесь ради экономии места возможны применение сухого академического стиля, сокращения, использование многочисленных отсылок к научной литературе. Они делаются так, как это принято у лингвистов: в тексте в скобках дается фамилия ученого, год издания научной работы и стр., к которой относится отсылка. 
Третья часть под названием «Библиография», доступ к которой будет также осуществляться через «тегу», предназначена как для широкого круга посетителей ВМСК, так и для ученых специалистов. Здесь можно будет найти краткий список научно-популярной литературы по заинтересовавшему посетителя вопросу, а также перечень и полные названия научных работ, на которые делались ссылки в разделе «Историография». Объем этой части не должен превышать 1 стандартной страницы текста, набранного 14 кеглем.

Сопровождающие статьи «Галлерии», также как и сейчас, будут содержать по 10 иллюстраций, связанных с самыми важными моментами статейных повествований.

Предлагаемый мной формат музейных статей позволяет гармонизировать распределение входящих в них материалов. Благодаря этому «экспозиция» ВМСК станет востребованной и желанной для самого широкого круга посетителей. Она будет полезна как неспециалистам, так и ученым. Особенно это касается герменевтических части музейных статей в их англоязычной версии, позволяющей ВМСК найти свою «нишу» среди специализированных печатных справочников и помогающей ему избежать некорректного сравнения с Википедией. Если учитывать, что английским языком в мире владеют 1,5 млрд. человек в мире, станет ясно, что создание ВМСК способно привести к настоящему прорыву в деле распространения знаний о культурах славянских народов в их историческом развитии. 